Article

\title{
Editorial: Sub- and Unconscious Information Processing in the Human Brain
}

\author{
Peter Walla $1,2,3$ (iD \\ 1 CanBeLab, Department of Psychology, Webster Vienna Private University, Praterstrasse 23, \\ 1020 Vienna, Austria; peter.walla@webster.ac.at \\ 2 School of Psychology, Newcastle University, Newcastle, 2308 Callaghan, Australia \\ 3 Faculty of Psychology, University of Vienna, 1010 Vienna, Austria
}

Received: 5 June 2018; Accepted: 7 June 2018; Published: 15 June 2018

\begin{abstract}
This Special Issue about sub- and unconscious information processing in the human brain finally became a collection of 6 accepted contributions, 2 articles, 2 reviews, 1 opinion and 1 concept paper. Even though more papers were submitted this rather small number of accepted contributions mirrors the still existing lack of focus on non-conscious human brain processes that surely influence human behavior to a much larger extent than one would ever imagine. Our brains contain evolutionary old neural structures that much more primitive organisms have in their brains too and crucially those old structures have more or the less the same functional properties regardless of what brain they belong to. Consciousness as an individual experience is a rather young evolutionary product, which means that those older structures that are strongly involved in the generation of human behavior work largely without being associated with conscious experience. This explains why people not always do what they say. In other words, the brain knows more than it admits to consciousness and since we have more and more access to that knowledge we should be interested in gaining it. The evidence grows that demonstrates how non-conscious processing occurs and influences our decision making.
\end{abstract}

Keywords: human brain; consciousness; information processing

While some of the non-conscious functions are very basic, others are involved in decision making and thus are definitely more complex. Since the function of the brain is to produce adapted behavior it certainly is the decision making part that is crucial to adaptation and thus to survival in both a very primitive, but also a highly developed sense in modern cultural societies. When it comes to decision making we all know that humans don't always do what they say, which is a result of their brain actually knowing more than it admits to consciousness, but how exactly and to what extent indeed our non-conscious mind triggers behavior is still largely unknown. However, objective science tools have revealed in multiple ways not only that non-conscious brain processes do exist, but also that they indeed reflect knowledge that is not accessible to consiousness. Some of such non-conscious information can never be consciously experienced, while other can, even though it currently isn't. For instance, in Rugg et al., 1998 [1] published electroencephalography (EEG) data reflective of non-conscious verbal memory (i.e., implicit memory) (see also Rugg et al., 1998 [2]). Between $300 \mathrm{~ms}$ and $500 \mathrm{~ms}$ after the onset of visually presented words, repeated words elicited distinct brain activity at posterior cortical sites regardless of those words being correctly recognised as repetitions or not while their related brain activity clearly differed from new words that were correctly identified as new. Over frontal electrode sites though repeated words that were not recognised as being repeated elicited brain activity that resembled brain activity elicited by correctly classified new words. So, the back side of the brain recognised word repetitions in the absence of conscious awareness. 
A whole series of more recent work utilising startle reflex modulation (SRM) reports about non-conscious affective processes that differ from conscious responses in various different conditions. Conscious aesthetic preference toward bottle shapes was shown to differ from non-conscious affective impact [3]. Preferences related to urban neighbourhoods were reported to be subject to discrepancies between conscious and non-conscious information processing [4]. Brand attitude can change non-consciously without affecting conscious processing [5-7] and emotion pictures are processed differently depending on conscious or non-conscious measures being taken $[8,9]$. SRM became a highly appreciated tool to quantify raw affective responses in the absence of any awareness and it got introduced to various different disciplines including clinical and industrial areas, even marketing [10-15]. Finally, the use of tools that are sensitive to non-conscious processes in the human brain have led to improved and more elaborated emotion models clearly distinguishing between affective processing (neural activity), feelings (felt bodily responses) and emotions (behavioral output communicating feelings; see [16-18]).

In that sense, all contributions of this Special Issue contribute to a better understanding of non-conscious brain processes. In the following, a short introduction to all contributions is provided.

One article has a focus on mental control of conscious, pre-conscious and unconscious affective responses to stressful events [19]. The authors include psychometric, behavioral and EEG measures and find that within the context of mindfullness practise a change from unnoticed information to conscious awareness of it should be understood as the most important first step for proper learning and self-empowerment. Finally, they highlight the function of a brain-sensing wearable device supporting mindfulness practises. This article is thus very applied by focussing on technical implications.

The second article highlights the benefit of completing survey-based investigations with objective measures in the context of pornography and violence exposure [20]. The authors report whether or not frequency of pornography use has an impact on non-conscious and/or conscious emotion processes. They find that conscious explicit ratings in response to emotion picture presentations were significantly different with respect to "Erotic" and "Pleasant" valence (pleasantness) ratings depending on pornography use. SRM shows marginal effects and EEG data show changes in relation to "Unpleasant" and "Violent" emotion picture categories that do not correlate with differences seen in the explicit ratings. Taken together, their findings suggest that increased pornography use has an influence on non-conscious neural responses to emotion-inducing stimuli which is not shown by explicit self-report.

Regardless of what "emotion"-definition one follows, it is fascinating to learn about the role of the cerebellum in unconscious and conscious processing of emotions [21]. The cerebellum is normally perceived as a rather basic structure supporting skillful behavior through integrating sensory and motor information. In their review paper, the authors elaborate on clinical, neuroimaging, and neurophysiological data that demonstrate cerebellar involvement in emotion-related information processing.

In the second review paper of this Special Issue, the author reports that psychotherapy with its various schools and different approaches can profit from meditation techniques supporting therapeutical interventions getting access to the non-conscious mind. While this may sound trivial and mainly important for the psychanalytic approach it is also beneficial for other schools. Fabbro et al. (2017) [22] provides an interesting overview of studies on the effects of meditation and dispositional mindfulness on conscious and non-conscious attitudes.

There is on ongoing discussion about consciousness and most often consciousness is seen as a process, a function that depends on neural activities. Pockett (2017) [23] contributes an opinion paper and with it challenges exactly that idea, namely that consciousness is a process. The author states that all neural processing is unconscious and that consciousness should be understood as a thing, not a process.

Finally, Lara-Rosano (2017) [24] provides a heuristic framework for non-conscious reasoning in the form of a concept paper. In this paper, the author argues that formal logic is a necessary 
but insufficient instrument for handling human reasoning. This is in line with the idea that pure algorithms will not be able to predict the future and also not to steer robots and make them more and more human-like. A while ago we started to realise that human beings make decisions not purely based on rational thinking, there is more to it and thus the author states that semantics, cognitive science, psychology and linguistics must complement logic to form the most appropriate analytical framework to understand and use conscious as well as non-conscious reasoning. The heuristic framework for non-conscious reasoning provided by the author is based on various different theories, some of which are mathematical models and the outcome or conclusion of this concept paper is of interest to those involved in the application of biological and neurological structures to the computational domain including artificial intelligence.

Let's continue and more strongly focus on investigations that strive to better understand non-conscious information processing in the human brain. It will help us to finally predict human behavior and to fix it when it goes wrong.

Conflicts of Interest: The authors declare no conflict of interest.

\section{References}

1. Rugg, M.D.; Mark, R.E.; Walla, P.; Schloerscheidt, A.M.; Birch, C.S.; Allan, K. Dissociation of the neural correlates of implicit and explicit memory. Nature 1998, 392, 595-598. [CrossRef] [PubMed]

2. Rugg, M.D.; Walla, P.; Schloerscheidt, A.M.; Fletcher, P.C.; Frith, C.D.; Dolan, R.J. Neural correlates of depth of processing effects on recollection: Evidence from brain potentials and PET. Exp. Brain Res. 1998, 123, 18-23. [CrossRef] [PubMed]

3. Grahl, A.; Greiner, U.; Walla, P. Bottle shape elicits gender-specific emotion: A startle reflex modulation study. Psychology 2012, 7, 548-554. [CrossRef]

4. Geiser, M.; Walla, P. Objective measures of emotion during virtual walks through urban neighbour-hoods. Appl. Sci. 2011, 1, 1-11. [CrossRef]

5. Bosshard, S.; Bourke, J.D.; Kunaharan, S.; Koller, M.; Walla, P. Established liked versus disliked brands: Brain activity, implicit associations and explicit responses. Cogent Psychol. 2016, 3, 1. [CrossRef]

6. Walla, P.; Koller, M.; Brenner, G.; Bosshard, S. Evaluative conditioning of established brands: Implicit measures reveal other effects than explicit measures. J. Neurosci. Psychol. Econ. 2017, 10, 24-41. [CrossRef]

7. Walla, P.; Koller, M.; Brenner, G.; Bosshard, S. Evaluative Conditioning of Brand Attitude-Comparing Explicit and Implicit Measures. In Proceedings of the Conference Paper Accepted for the 2016 European Marketing Academy Conference, Oslo, Norway, 22-24 May 2016.

8. Mavratzakis, A.; Molloy, E.; Walla, P. Modulation of the startle reflex during brief and sustained exposure to emotional pictures. Psychology 2013, 4, 389-395. [CrossRef]

9. Walla, P.; Rosser, L.; Scharfenberger, J.; Duregger, C.; Bosshard, S. Emotion ownership: Different effects on explicit ratings and implicit responses. Psychology 2013, 3A, 213-216. [CrossRef]

10. Koller, M.; Walla, P. Towards alternative ways to measure attitudes related to consumption: Introducing startle reflex modulation. J. Agric. Food Ind. Organ. 2015, 13, 83-88. [CrossRef]

11. Koller, M.; Walla, P. Measuring Affective Information Processing in Information Systems and Consumer Research-Introducing Startle Reflex Modulation. In Proceedings of the ICIS Proceedings, Breakthrough Ideas, Full Paper in Conference Proceedings, Orlando, FL, USA, 14 December 2012.

12. Lyons, G.S.; Walla, P.; Arthur-Kelly, M. Toward improved ways of knowing children with profound multiple disabilities(PMD): Introducing startle reflex modulation. Dev. Neurorehabilit. 2013, 16, 340-344. [CrossRef] [PubMed]

13. Walla, P.; Schweiger, M. Samsung Versus Apple: Smartphones and Their Conscious and Non-conscious Affective Impact. In Information Systems and Neuroscience; Full Conference paper in Information Systems and Neuroscience of the Series Lecture Notes in Information Systems and Organisation; Springer: Cham, Switzerland, 2017; Volume 16, pp. 73-82.

14. Walla, P.; Koller, M.; Meier, J. Consumer neuroscience to inform consumers-Physiological methods to identify attitude formation related to over-consumption and environmental damage. Front. Hum. Neurosci. 2014, 8, 304. [CrossRef] [PubMed] 
15. Walla, P.; Brenner, G.; Koller, M. Objective measures of emotion related to brand attitude: A new way to quantify emotion-related aspects relevant to marketing. PLoS ONE 2011, 6, e26782. [CrossRef] [PubMed]

16. Mavratzakis, A.; Herbert, C.; Walla, P. Emotional facial expressions evoke faster orienting responses, but weaker emotional responses at neural and behavioural levels compared to scenes: A simultaneous EEG and facial EMG study. Neuroimage 2016, 124, 931-946. [CrossRef] [PubMed]

17. Walla, P. Affective Processing Guides Behavior and Emotions Communicate Feelings: Towards a Guideline for the NeuroIS Community. In Information Systems and Neuroscience. Lecture Notes in Information Systems and Organisation; Davis, F., Riedl, R., vom Brocke, J., Léger, P.M., Randolph, A., Eds.; Springer: Cham, Switzerland, 2018; Volume 25.

18. Walla, P.; Koller, M. Emotion is not what you think it is: Startle Reflex Modulation (SRM) as a measure of affective processing in NeuroIs. In Information Systems and Neuroscience; NeuroIs Conference Proceedings; Springer: Cham, Switzerland, 2015.

19. Balconi, M.; Fronda, G.; Venturella, I.; Crivelli, D. Conscious, Pre-Conscious and Unconscious Mechanisms in Emotional Behaviour. Some Applications to the Mindfulness Approach with Wearable Devices. Appl. Sci. 2017, 7, 1280. [CrossRef]

20. Kunaharan, S.; Halpin, S.; Sitharthan, T.; Bosshard, S.; Walla, P. Conscious and Non-Conscious Measures of Emotion: Do They Vary with Frequency of Pornography Use? Appl. Sci. 2017, 7, 493. [CrossRef]

21. Clausi, S.; Iacobacci, C.; Lupo, M.; Olivito, G.; Molinari, M.; Leggio, M. The Role of the Cerebellum in Unconscious and Conscious Processing of Emotions: A Review. Appl. Sci. 2017, 7, 521. [CrossRef]

22. Fabbro, A.; Crescentini, C.; Matiz, A.; Clarici, A.; Fabbro, F. Effects of Mindfulness Meditation on Conscious and Non-Conscious Components of the Mind. Appl. Sci. 2017, 7, 349. [CrossRef]

23. Pockett, S. Consciousness Is a Thing, Not a Process. Appl. Sci. 2017, 7, 1248. [CrossRef]

24. Lara-Rosano, F. An Heuristic Framework for Non-Conscious Reasoning. Appl. Sci. 2017, 7, 1161. [CrossRef]

(C) 2018 by the author. Licensee MDPI, Basel, Switzerland. This article is an open access article distributed under the terms and conditions of the Creative Commons Attribution (CC BY) license (http:/ / creativecommons.org/licenses/by/4.0/). 